\title{
Increased food production and reduced water use through optimized crop distribution
}

\author{
Kyle Frankel Davis ${ }^{1,2,3 \star}$, Maria Cristina Rullii, Antonio Seveso ${ }^{4}$ and Paolo D'Odorico, ${ }^{1,5}$
}

\begin{abstract}
Growing demand for agricultural commodities for food, fuel and other uses is expected to be met through an intensification of production on lands that are currently under cultivation. Intensification typically entails investments in modern technology such as irrigation or fertilizers - and increases in cropping frequency in regions suitable for multiple growing seasons. Here we combine a process-based crop water model with maps of spatially interpolated yields for 14 major food crops to identify potential differences in food production and water use between current and optimized crop distributions. We find that the current distribution of crops around the world neither attains maximum production nor minimum water use. We identify possible alternative configurations of the agricultural landscape that, by reshaping the global distribution of crops within current rainfed and irrigated croplands based on total water consumption, would feed an additional 825 million people while reducing the consumptive use of rainwater and irrigation water by $14 \%$ and $12 \%$, respectively. Such an optimization process does not entail a loss of crop diversity, cropland expansion or impacts on nutrient and feed availability. It also does not necessarily invoke massive investments in modern technology that in many regions would require a switch from smallholder farming to large-scale commercial agriculture with important impacts on rural livelihoods.
\end{abstract}

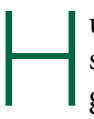
uman demand for crop production is expected to increase substantially in the coming decades as a result of population growth, richer diets and biofuel use. For food production to keep pace, unprecedented amounts of resources - such as water, fertilizers and energy - will be required. With humankind already exceeding 'sustainable' levels in numerous ways ${ }^{1-3}$, calls for 'sustainable intensification' - in which yields are enhanced on existing croplands while seeking to minimize impacts on water and other agricultural resources - have increased in frequency and urgency. Recent studies have quantified aspects of this, showing that there is a large potential to improve crop yields ${ }^{4}$ and increase harvest frequencies $^{5}$ to better meet future human demand ${ }^{6}$. Although promising, such solutions would necessitate major investments in modern technology and large additional inputs of water and fertilizer $^{7}$. Similarly, recent work has shown that increases in the efficiency of resource use within the food system will not be able to keep pace with growing human demand ${ }^{8,9}$. Thus, unless society can find new solutions aimed at achieving sustainable agriculture, the environmental burden of food production will necessarily continue to increase.

Slowing the increase in water use for agriculture remains a formidable challenge. Recent years have seen the emergence of water-stressed conditions in some of the planet's most important agricultural areas (for example, California, India, Australia), resulting from a confluence of factors: demographic pressure ${ }^{10}$, transboundary water allocations ${ }^{11}$, mismanaged water resources ${ }^{12}$ and, at times, extreme climate events ${ }^{13}$. Moreover, the use of flexible crops for energy purposes can engender competition for water between the food and energy sectors in water-stressed areas ${ }^{14}$. As agriculture accounts for the vast majority of society's freshwater demand ${ }^{15}$, there is a growing need for creative yet practical approaches to address the massive water footprint of crop production, particularly in areas that experience regular water scarcity ${ }^{16,17}$ or that have limited access to agricultural technologies, particularly in light of the potential impacts of climate change on irrigation water availability $^{18}$. Although recent work has highlighted that a combination of 'hard' (for example, reservoir capacity, desalinization) and 'soft' (irrigation efficiency, per capita water demand) solutions can substantially reduce water stress, it has also indicated that serious obstacles - be they economic, health-related, infrastructural or environmental - stand in the way of realizing these solutions ${ }^{19}$. It is therefore essential that strategies aimed at sustainable water use better integrate food security, socio-economy and the environment. Incorporating these multiple considerations, one potential solution that has received little attention outside of case study examples ${ }^{20-22}$ is whether the current distribution of crops is, in fact, optimal for minimizing the water demand of crop production.

Here we combine a process-based crop water model with maps of spatially interpolated yields for 14 major food crops to identify differences between current crop distributions and where they can most suitably be planted on rainfed and irrigated croplands. In redistributing crops across currently cultivated lands, we determine what pattern of crops would minimize the green and blue water demand of crop production - supplied through precipitation and irrigation, respectively - while also increasing production in terms of calories and protein. We then examine the magnitude of potential water savings from shifting crops and compare this with other proposed strategies for agricultural water conservation (such as more crop per drop ${ }^{23}$; increased irrigation efficiency ${ }^{24}$; decreased animal protein in diets ${ }^{25}$; minimizing food waste $^{26}$ ). In doing this, we attempt to identify crop configurations that will leave rainfed production less susceptible to dry spells and reduce water consumption, thereby potentially enhancing environmental flows ${ }^{27}$, in irrigated systems. Our study seeks to provide a novel multidimensional approach that leverages existing locally available technologies and knowledge and integrates food security, water sustainability, and rural livelihoods.

\footnotetext{
'Department of Environmental Sciences, University of Virginia, Charlottesville, VA, USA. ${ }^{2}$ The Earth Institute, Columbia University, New York, NY, USA. ${ }^{3}$ The Nature Conservancy, New York, NY, USA. ${ }^{4}$ Department of Civil and Environmental Engineering, Politecnico di Milano, Milan, Italy. ${ }^{5}$ Department of Environmental Science, Policy, and Management, University of California, Berkeley, CA, USA. *e-mail: kd2620@columbia.edu
} 


\section{The benefits of crop redistribution}

We find that optimizing the global distribution of major crops reduced the consumptive use of green and blue water by $13.6 \%$ and $12.1 \%$, respectively, relative to current levels (Fig. 1). This water saving was also accompanied by increases in calorie $(+10 \%)$ and protein $(+19 \%)$ production, global feed availability $(+51 \%)$, and the supply of 18 other nutrients (Fig. 2, Supplementary Tables 1 and 2). The volume of potential water savings from rearranging crops (green: $416 \mathrm{~km}^{3} \mathrm{yr}^{-1}$; blue: $56 \mathrm{~km}^{3} \mathrm{yr}^{-1}$ ) is more than double that of current water consumption for biofuel production (green: $164 \mathrm{~km}^{3} \mathrm{yr}^{-1}$; blue: $\left.22 \mathrm{~km}^{3} \mathrm{yr}^{-1}\right)^{14}$ and could substantially reduce global groundwater depletion $\left(283 \mathrm{~km}^{3} \mathrm{yr}^{-1}\right)^{28}$. Furthermore, the additional calories and protein from this approach could feed 825 million more people.

Globally, such improvements were achieved by increasing the production of groundnuts, roots, soybeans, sorghum and tubers, while substantially moving away from millets, rice, sugar crops and wheat (Fig. 3). However, the nature of specific interchanges varied widely among countries and between rainfed and irrigated production (Supplementary Tables 3-6). For instance, rainfed sorghum, soybeans, tubers, and wheat replaced much of the millets, sugar beet and sunflower in western Russia. Irrigated maize, millets, roots and tubers supplanted rice, sorghum and wheat in northern India. Rainfed rapeseed, sugar cane and wheat were substituted by maize, soybeans and tubers in Australia. And groundnuts, maize and sorghum took priority over sugar beet and wheat in the Nile Delta. Many other regions (such as Sub-Saharan Africa and South Asia) experienced redistributions involving greater numbers of crops (Supplementary Figures 1-14).

Although the global advantages of this strategy are clear, certain countries benefited more than others (Fig. 3, Supplementary Tables 7-12). We found substantial water savings - at least $20 \%$ of the current water demand for crop production - for 42 countries, many of which frequently experience water stress (examples include Australia, India, Mexico, Morocco and South Africa). In addition, 63 countries, most of which rely on food imports to meet domestic demand (such as Ethiopia, Iran, Kenya and Spain), would experience a greater than $20 \%$ increase in either calorie or protein production by redistributing crops (Fig. 3). These localized benefits were also mirrored in our examination of water scarcity. Our replacement approach realized substantial water savings across the
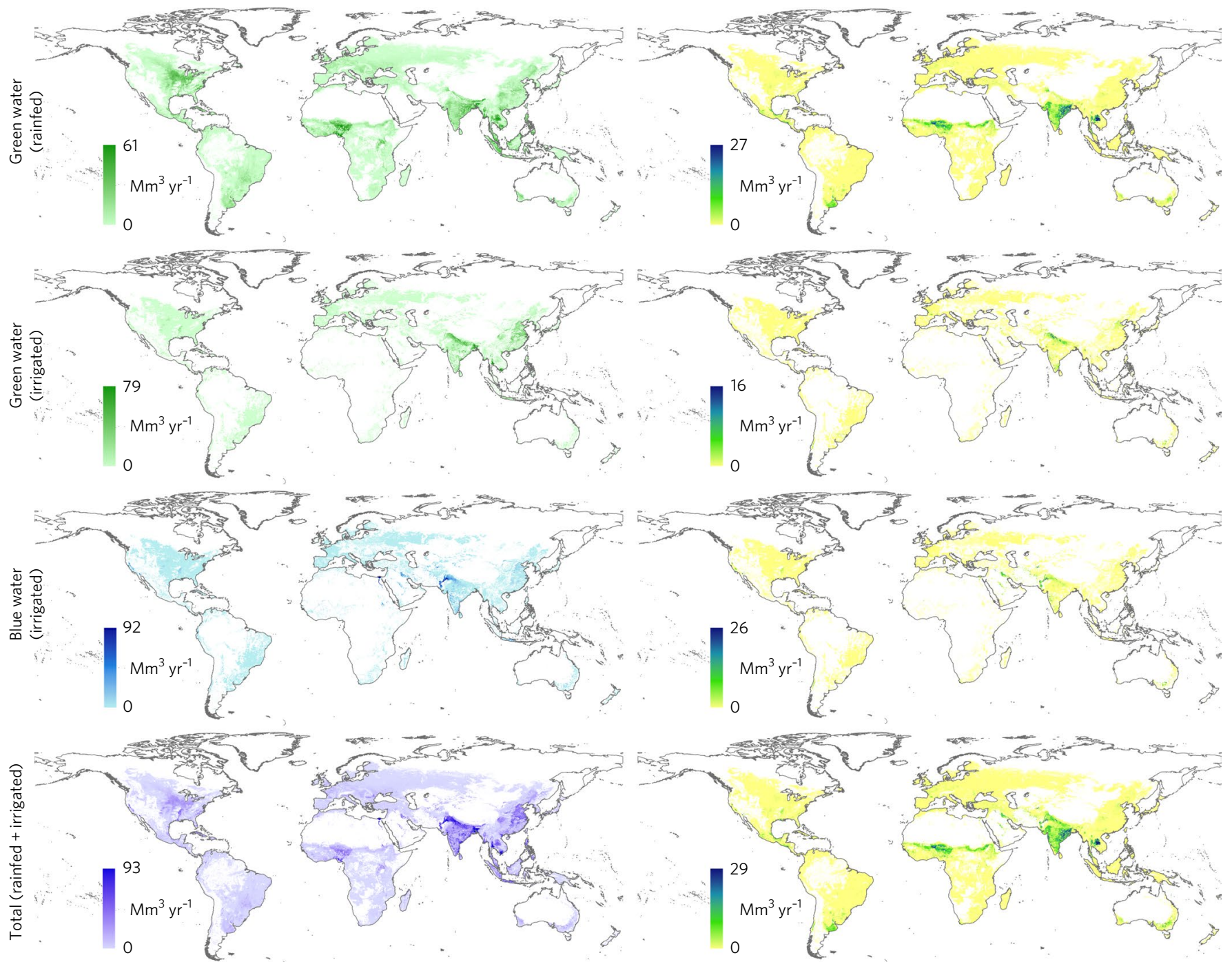

Fig. 1 | Potential annual water savings from redistributing major crops across currently cultivated lands. Crop replacement was performed separately for rainfed and irrigated croplands. Maps in the left-hand column show the current distribution of consumptive water use. Maps in the right-hand column show the reduction in consumptive water use as a result of crop redistribution; a higher value indicates a greater reduction in water use relative to current levels. 

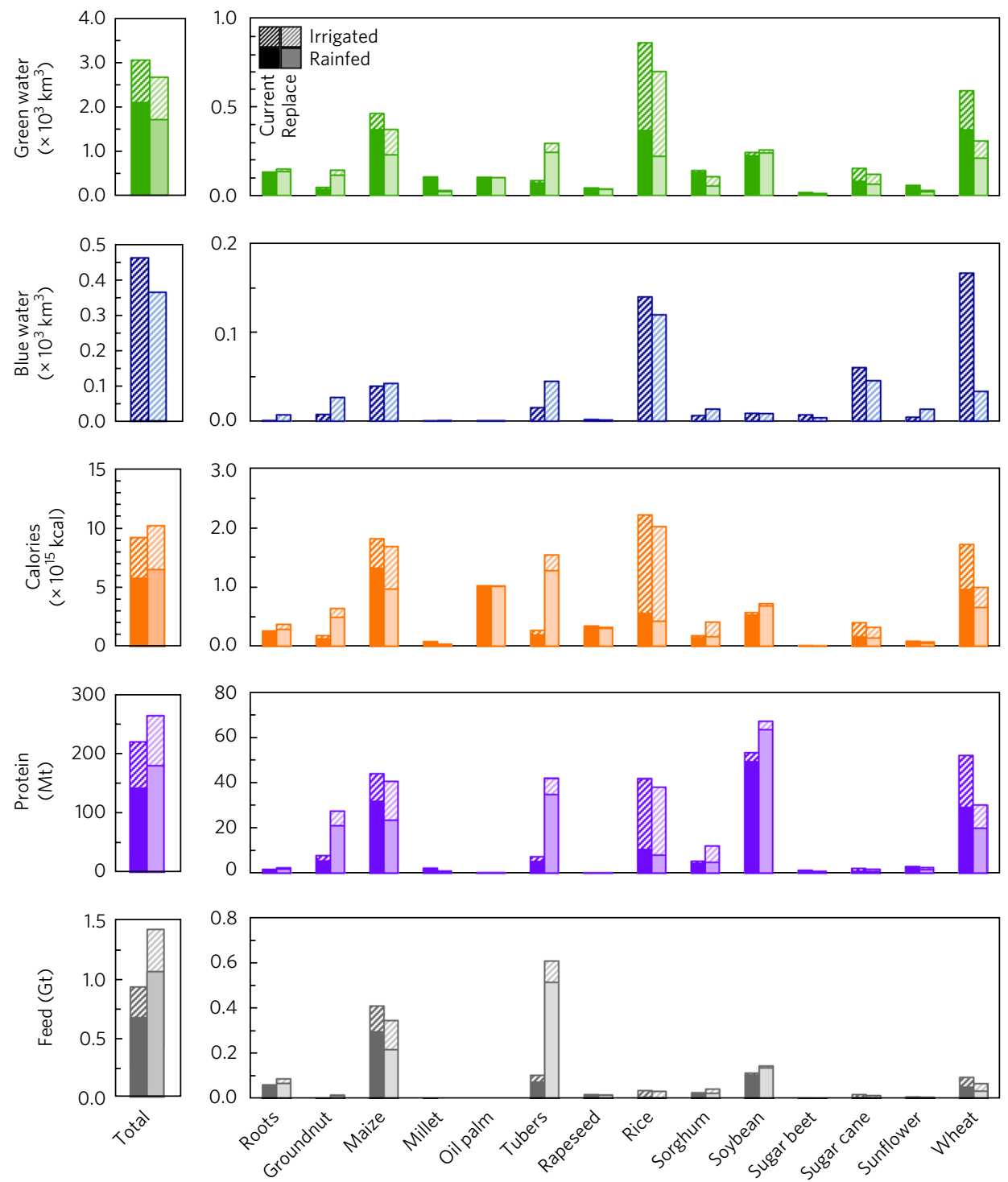

Fig. 2 | Global crop-specific changes in consumptive water use, nutrient production and feed supply due to redistributing crops in currently cultivated lands. The left-hand plots show the total changes in water use and nutrient production across all crops.

planet's cultivated lands, but water demand in stressed regions where water consumption exceeds annual availability - was only reduced below renewable levels for Africa's Sahel (Fig. 4). Water scarcity persisted in many other important agricultural areas (the US Midwest, northern India, Australia's Murray-Darling Basin, for example), indicating that extensive crop production in these places prohibits water sustainability, regardless of crop choice. Alternative replacement scenarios yielded similar benefits in terms of water savings and increased production (Supplementary Table 13).

\section{Minimizing tradeoffs across multiple dimensions}

Identifying synergies is essential for the sustainable intensification of agriculture. Our analysis shows that redistributing crops across lands that are cultivated at present can make use of the technologies and knowledge that are already present in a country to offer distinct benefits across food security and environmental spheres. In particular, our results are encouraging for several world regions that are grappling with water scarcity, food insecurity, or a combination of both ${ }^{17}$. We observed substantial water savings in economically important agricultural areas such as southeastern Australia, the Indo-Gangetic basin, the Nile Delta and California's Central Valley.
There were also important increases in food supply in other areas the Sahel, eastern China, southern Africa and Mexico. It is therefore apparent that the strategy of redistributing crops within cultivated lands can help to sustainably increase the food self-sufficiency of nations, thereby reducing their dependence on food imports as well as their associated exposure to disturbances beyond their boundaries ${ }^{29}$.

Reductions in water footprint also often correlate with other environmental benefits (such as decreased nitrogen application and land use $)^{30}$. In the case of this study, the extensive increases in soybean crops that we observed can aid in reducing synthetic fertilizer requirements in many cultivated areas. By conserving the overall extent of cultivated lands (that is, intensification), our approach also allows the opportunity for substantial land sparing ${ }^{31}$. In addition, minimizing the production of 'empty-nutrient' crops (such as sugar beet and sugar cane) can have corresponding health benefits ${ }^{32}$. Such improvements in the water footprint of both rainfed and irrigated crop production through the use of crops that are less waterdemanding also help to increase the climate resilience of a country's agricultural system, as crops with lower water requirements are less likely to undergo crop water stress under more variable future 


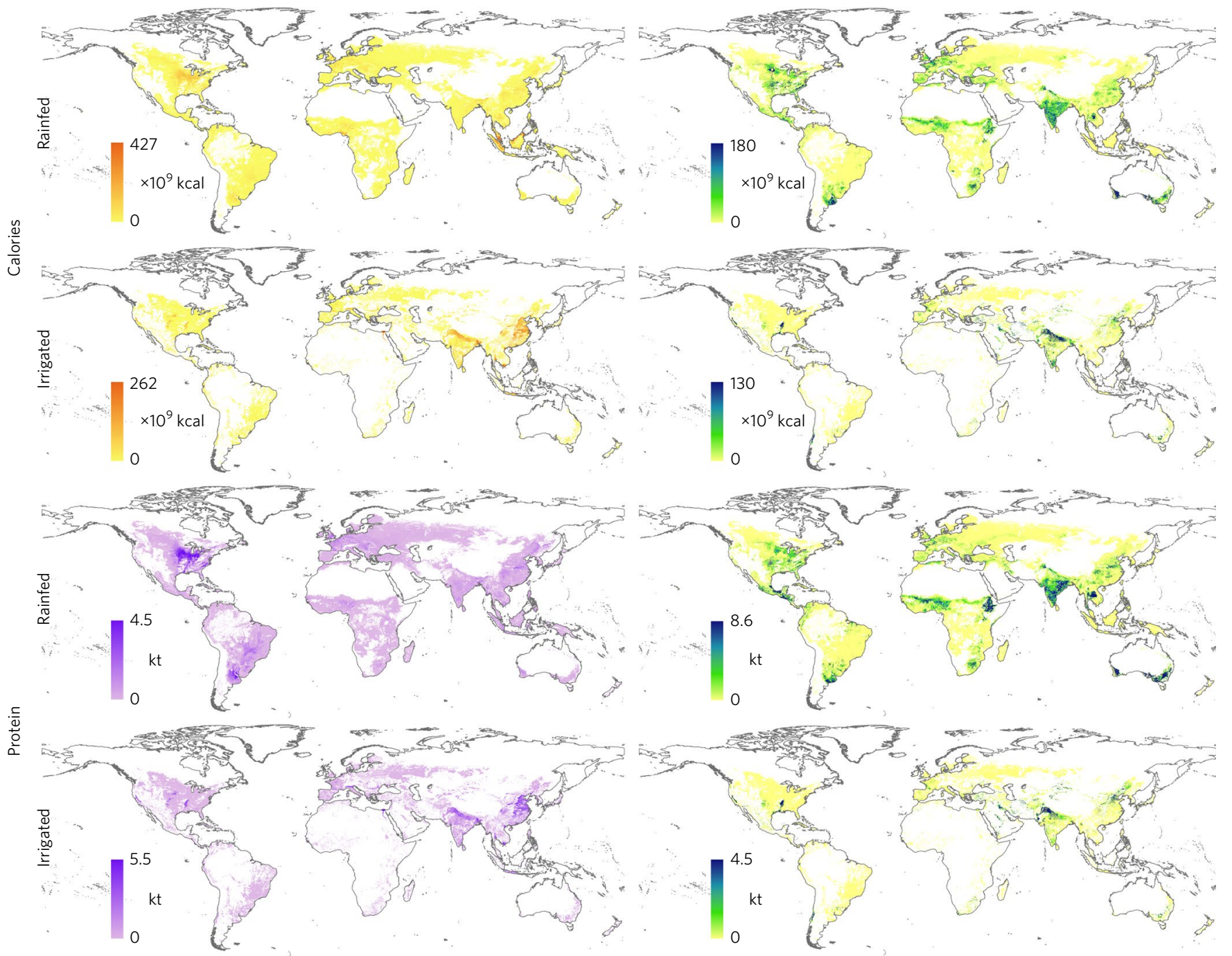

Fig. 3 | Spatial distribution of increases in calorie and protein production from crop redistribution. Maps in the left-hand column show the current distribution of calorie and protein production from major food crops on rainfed and irrigated areas. Maps in the right-hand column show the increase in nutrient production as a result of crop redistribution relative to current levels.

climate conditions. Relatedly, crop replacement did not adversely affect the indicators of resilience that we consider in the current system as our replacement criteria explicitly required crop diversity to be maintained. This is in contrast to yield gap closure and other methods of agricultural intensification which - by promoting maximized production and transitions toward monoculture may eliminate redundancy and diversity within agroecosystems ${ }^{33}$ and render agriculture more vulnerable to droughts, pests and other shocks.

The water savings and production increases from redistributing crops are also substantial compared with other solutions that have recently been presented in the literature (Table 1 ). With more than a than doubling in irrigation water demand required to close the crop yield gap under current technologies ${ }^{7}$, a suite of solutions (and their cumulative water savings and food supply increases) will be necessary to achieve sustainable agricultural pathways with the water resources that are available for agricultural uses. Of course, there are probably cultural barriers and dietary preferences that may limit the application of this strategy in certain ways - considerations that may be better accommodated in future analyses by constraining the production quantities of each crop. This approach would also need to account for the complete set of accompanying economic and environmental costs as well as unique factors local to the place of its implementation (for example, the potential for multiple harvests per year ${ }^{5}$ ). As such, the spatial and temporal resolution utilized in this study is not suitable to make fine-scale assessments, as detailed crop data are essential to ensure reliable recommendations for crop replacements at the local scale. Nonetheless, the apparent benefits of crop replacement make it a viable potential strategy for the sustainable intensification of agriculture and offer an alternative to the large investments - and subsequent transition from smallholder farming to commercial agriculture - that are often deemed requisite to close the technology and yield gaps of many developing nations. In this context, we also stress that the crop replacement criteria used in this study prevent losses in crop diversity, losses in feed availability and nutrient supply or major depletion of soil nutrients. Therefore, by and large this analysis does not replace a heterogeneous agricultural landscape with monoculture, a transition that would raise concerns for the potential losses of resistance to pests and climate extremes, and possible impacts on rural livelihoods ${ }^{33}$.

\section{Holistic solutions for a sustainable food system}

It is clear from the results presented here that only by considering nutrition and natural resources together is it possible to formulate truly sustainable solutions for the global food system. The approach utilized in this study also offers many potential avenues 


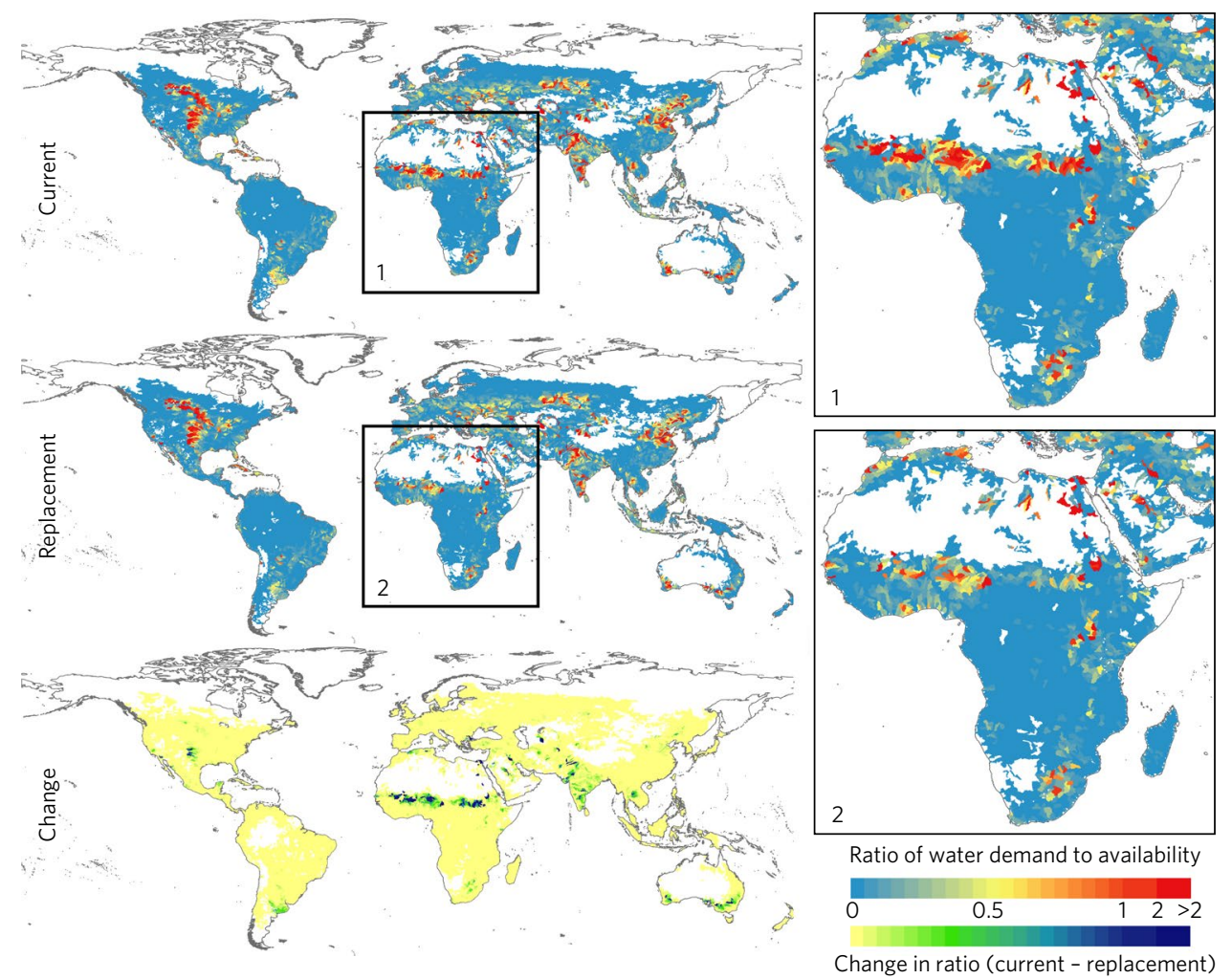

Fig. 4 | Ratio of total crop water demand to renewable water availability. Watersheds with $<1 \mathrm{~km}^{3} \mathrm{yr}^{-1}$ of renewable water availability (that is, water provided by precipitation within the watershed and/or upstream inflows that are stored in or pass through the watershed annually ${ }^{17}$ ) are not shown.

for future work. These include considering different climate scenarios, accounting for other crops and crop uses, incorporating other environmental impacts (such as fertilizer use) and imposing a greater number of constraints in the optimization criteria - for example, only substituting crops within a crop group (cereals, for example). The concept of crop redistribution can also be combined with other strategies for water savings (such as drip irrigation or selective breeding) to better achieve sustainable intensification ${ }^{8,34}$. Future work should also identify the economic, political, and cultural obstacles that have prevented an optimized crop distribution to date.

The confluence of demographic growth and climate change means that there is a pressing need to implement strategies within

\begin{tabular}{|c|c|c|c|}
\hline Solution & $\begin{array}{l}\text { Potential } \\
\text { water savings } \\
\left(\mathrm{km}^{3} \mathrm{yr}^{-1}\right)\end{array}$ & $\begin{array}{l}\text { Production } \\
\text { increase } \\
\left(10^{15} \mathrm{kcal}\right)\end{array}$ & Reference \\
\hline Crop redistribution & $\begin{array}{l}416 \text { (green) } \\
56 \text { (blue) }\end{array}$ & 1.4 & This study \\
\hline $\begin{array}{l}\text { Improvements in crop } \\
\text { water productivity }\end{array}$ & 77 & 0.1 & 23 \\
\hline $\begin{array}{l}\text { Promote irrigation } \\
\text { efficiency }\end{array}$ & 292 & 2.5 & 24,34 \\
\hline $\begin{array}{l}\text { Minimization of food } \\
\text { waste }\end{array}$ & 78 & 0.7 & 26 \\
\hline $\begin{array}{l}\text { Reduced dietary protein } \\
\text { from animal products } \\
(25 \% \text { of total) }\end{array}$ & 683 & - & 25 \\
\hline
\end{tabular}

the agricultural sector to simultaneously increase food production and alleviate water stress ${ }^{17}$. New and existing approaches to water conservation must be utilized where appropriate to ensure sustainable growth in the global food system. Integrating food security, socioeconomics and the environment will be critical in pursuing the sustainable development of agriculture. This study demonstrates the potential efficacy of crop replacement in achieving these multiple objectives; provides an alternative strategy to investmentdemanding, intensified agricultural production; and makes use of locally available agricultural technologies and knowledge.

\section{Methods}

Methods, including statements of data availability and any associated accession codes and references, are available at https://doi. org/10.1038/s41561-017-0004-5.

Received: 19 July 2017; Accepted: 3 October 2017;

Published online: 06 November 2017

\section{References}

1. Wackernagel, M. et al. Tracking the ecological overshoot of the human economy. Proc. Natl Acad. Sci. USA 99, 9266-9271 (2002).

2. Hoekstra, A. Y. \& Wiedmann, T. O. Humanity's unsustainable environmental footprint. Science 344, 1114-1117 (2014).

3. Steffen, W. et al. Planetary boundaries: Guiding human development on a changing planet. Science 347, 736 (2015).

4. Mueller, N. D. et al. Closing yield gaps through nutrient and water management. Nature 490, 254-257 (2012).

5. Ray, D. K. \& Foley, J. A. Increasing global crop harvest frequency: recent trends and future directions. Environ. Res. Lett. 8, 044041 (2013).

6. Davis, K. F., D'Odorico, P. \& Rulli, M. C. Moderating diets to feed the future. Earth Future 2, 559-565 (2014).

7. Davis, K. F. et al. Water limits to closing yield gaps. Adv. Water Res. 99, 67-75 (2017). 
8. Davis, K. F. et al. Meeting future food demand with current agricultural resources. Glob. Environ. Change 39, 125-132 (2016).

9. van Ittersum, M. K. et al. Can sub-Saharan Africa feed itself? Proc. Natl Acad. Sci. USA 113, 14964-14969 (2016).

10. Porkka, M., Gerten, D., Schaphoff, S., Siebert, S. \& Kummu, M. Causes and trends of water scarcity in food production. Environ. Res. Lett. 11, 015001 (2016).

11. Munia, H. et al. Water stress in global transboundary river basins: significance of upstream water use on downstream stress. Environ. Res. Lett. 11, 014002 (2016).

12. Rodell, M., Velicogna, I. \& Famiglietti, J. S. Satellite-based estimates of groundwater depletion in India. Nature 460, 999-1002 (2009).

13. Famiglietti, J. S. The global groundwater crisis. Nat. Clim. Change 4, 945-948 (2014).

14. Rulli, M. C., Bellomi, D., Cazzoli, A., De Carolis, G. \& D’Odorico, P. The water-land-food nexus of first-generation biofuels. Sci. Rep. 6, 22521 (2016)

15. Hoekstra, A. Y. \& Mekonnen, M. M. The water footprint of humanity. Proc. Natl Acad. Sci. USA 109, 3232-3237 (2012).

16. Hoekstra, A. Y., Mekonnen, M. M., Chapagain, A. K., Mathews, R. E. \& Richter, B. D. Global monthly water scarcity: blue water footprints versus blue water availability. PLoS ONE 7, e32688 (2012).

17. Brauman, K. A., Richter, B. D., Postel, S., Malsy, M. \& Flörke, M. Water depletion: An improved metric for incorporating seasonal and dry-year water scarcity into water risk assessments. Elementa 4, 000083 (2016).

18. Elliot, J. et al. Constraints and potentials of future irrigation water availability on agricultural production under climate change. Proc. Natl Acad. Sci. USA 111, 3239-3244 (2014).

19. Wada, Y., Gleeson, T. \& Esnault, L. Wedge approach to water stress. Nat. Geosci. 7, 615-617 (2014).

20. Tarjuelo, J. M., de Juan, J. A., Valiente, M. \& García, P. Model for optimal cropping patterns within the farm based on crop water production functions and irrigation uniformity II: a case study of irrigation scheduling in Albacete, Spain. Agric. Water Manag. 31, 145-163 (1996)

21. Cooley, H., Christian-Smith, J. \& Gleick, P. More with Less: Agricultural Water Conservation and Efficiency in California - A Special Focus on the Delta (Pacific Institute, Oakland, 2008)

22. Devineni, N., Perveen, S. \& Lall, U. Shifting Crops, Saving Water (Columbia Water Center, The Earth Institute, 2011).

23. Brauman, K. A., Siebert, S. \& Foley, J. A. Improvements in crop water productivity increase water sustainability and food security-a global analysis. Environ. Res. Lett. 8, 024030 (2013).

24. Jägermeyr, J. et al. Water savings potentials of irrigation systems: global simulation of processes and linkages. Hydrol. Earth. Syst. Sci. 19, 3073-3091 (2015).

25. Jalava, M., Kummu, M., Porkka, M., Siebert, S. \& Varis, O. Diet change-a solution to reduce water use? Environ. Res. Lett. 9, 091003 (2014).
26. Kummu, M. et al. Lost food, wasted resources: global food supply chain losses and their impacts on freshwater, cropland, and fertiliser use. Sci. Tot. Environ. 438, 477-489 (2012).

27. Poff, N. L. et al. The ecological limits of hydrologic alteration (ELOHA): a new framework for developing regional environmental flow standards. Freshwat. Biol. 55, 147-170 (2009).

28. Wada, Y. et al. Global depletion of groundwater resources. Geophys. Res. Lett. 37, L20402 (2010)

29. Suweis, S., Carr, J. A., Maritan, A., Rinaldo, A. \& D’Odorico, P. Resilience and reactivity of global food security. Proc. Natl Acad. Sci. USA 112, 6902-6907 (2015).

30. Gephart, J. A. et al. The environmental cost of subsistence: Optimizing diets to minimize footprints. Sci. Tot. Environ. 553, 120-127 (2016).

31. Phalan, B. et al. How can higher-yield farming help to spare nature? Science 351, 450-451 (2016).

32. Tilman, D. \& Clark, M. Global diets link environmental sustainability and human health. Nature 515, 518-522 (2014)

33. Walker, B. \& Salt, D. Resilience Thinking (Island, Washington DC, 2006).

34. Jägermeyr, J. et al. Integrated crop water management might sustainably halve the global food gap. Environ. Res. Lett. 11, 025002 (2016).

\section{Acknowledgements}

We thank M. R. Smith for providing information on crop nutrient content. We thank J. Gephart for her useful input regarding optimization approach. This work was supported by The Nature Conservancy's NatureNet Science Fellows programme.

\section{Author contributions}

K.F.D., A.S., M.C.R. and P.D. designed the experiment. K.F.D. and A.S. performed the analysis. K.F.D., M.C.R. and P.D. wrote the paper.

\section{Competing interests}

The authors declare no competing financial interests.

\section{Additional information}

Supplementary information is available for this paper at https://doi.org/10.1038/ s41561-017-0004-5.

Reprints and permissions information is available at www.nature.com/reprints. Correspondence and requests for materials should be addressed to K.F.D.

Publisher's note: Springer Nature remains neutral with regard to jurisdictional claims in published maps and institutional affiliations. 


\section{Methods}

Crop definitions. We consider 14 major food crops/groups: groundnut, maize, millet, oil palm, rapeseed, rice, roots (cassava; plantain; yam; other roots), sorghum, soybean, sugar beet, sugarcane, sunflower, tubers (potato; sweet potato) and wheat. These crops account for $72 \%$ of global crop production, $70 \%$ of global harvested area, $75 \%$ of all feed use, $83 \%$ of vegetal calories in the diet and $78 \%$ of dietary protein contributed by vegetal sources ${ }^{35}$. Owing to a combination of data limitations and substantial within-group variety for certain food groups, we do not consider vegetables, fruits or pulses and assume that their production remains constant and unaffected under crop replacement. Spatially distributed ( 5 arc minute; $1 / 12^{\circ} ; \sim 10-\mathrm{km}$ resolution), crop-specific information on rainfed/irrigated yields $\left(\right.$ tonne ha ${ }^{-1}$ ), rainfed/irrigated harvested area (ha) and rainfed/irrigated agro-ecological suitability were taken from the Global Agroecological Zones (GAEZ) database of the Food and Agriculture Organization of the United Nations (FAO) ${ }^{36}$. Agro-ecological suitability (represented as a) describes the biophysical constraints (such as soil, terrain, temperature and precipitation regimes) that may limit a farmer from realizing the maximum attainable yield of a crop. Crop definitions for this data set closely matched those used in FAOSTAT ${ }^{35}$ with the exception of cassava and potatoes. In this study, we used the GAEZ 'Roots' data (cassava, cocoyam, plantains and yam) to represent cassava and the GAEZ tubers data (potato and sweet potato) to represent potatoes (Supplementary Table 14)

Per-capita demand for calories $\left(2,724 \mathrm{kcal} \mathrm{day}^{-1} ; 16 \%\right.$ from animal products $)$ and protein $\left(75 \mathrm{~g} \mathrm{day}^{-1}\right)$ were global averages for the year $2000^{35}$. Following an earlier study $\mathrm{y}^{37}$, calories for the portion of the diet coming from animal products were multiplied by a calorie input-output ratio of 2.4 that balances the feed calories consumed with the animal calories produced in the year $2000^{35}$ (Supplementary Table 15). The resultant diet was then expressed in equivalent vegetal calories $\left(3,343 \mathrm{kcal} \mathrm{day}^{-1}\right)$. As noted before, while approximately half of the animal calories included in the human diet are supported by biomass sources not included in our analysis (such as grasses, roughage) ${ }^{6}$, we assume that this biomass will remain available and have shown that feed availability from the major crops considered here would increase under crop replacement (Supplementary Table 1). Per tonne crop values (US\$ tonn $\mathrm{e}^{-1}$ ) were calculated as the global productionweighted average of producer prices (year 2010) s. $^{35}$. These values represent the price charged by a farmer at farm gate or at the first point-of-sale and therefore incorporate input costs as passed on to the consumer. Information on nutrient content was taken from the Global Extended Nutrient Supply (GENuS) database ${ }^{38}$ (Supplementary Table 2).

Crop consumptive water use (CWU) (that is, the amount of water required to compensate for a crop's evapotranspiration losses) was calculated using several different input data sets. Long-term average monthly precipitation data $(10 \mathrm{arcmin}$; 1961-1990) were taken from the University of East Anglia's Climate Research Unit CRU CL2.0 data set ${ }^{39}$. Crop coefficients, planting dates, and growing stages were adapted from a previous study ${ }^{40}$ (Supplementary Table 16), and the same climate zones were used, adapted from an earlier work (Supplementary Figure 15). The total available water capacity for the dominant soil $(5 \mathrm{arcmin})$ came from the Harmonized World Soil Database ${ }^{42}$

All of the data used in this study are publically available or included in the Supplementary Information. In addition, the data that support the findings of this study are available upon request from the corresponding author.

Consumptive water use of rainfed and irrigated crops. Long-term average monthly reference evapotranspiration $\left(\mathrm{ET}_{0}\right.$; measured in $\mathrm{mm} \mathrm{month}^{-1}$, 10 arcmin; 1961-1990) was taken from the $\mathrm{FAO}^{43}$. Each pixel was resampled into 4 new cells to obtain a 5 arcmin resolution and divided by the number of days in the corresponding month to convert from monthly to daily values. The actual evapotranspiration $\left(\mathrm{ET}_{\mathrm{a}}\right)$ of crop $i$ on day $t$ was then calculated as:

$$
E T_{a, i, t}=k_{c, i, t} k_{s, i, t} E T_{o, t}
$$

where $k_{c, i, t}$ is the crop coefficient of crop $i$ corresponding to the month in which day $t$ occurs (Supplementary Table S16), and $k_{\mathrm{s}, \mathrm{i}, \mathrm{i}}$ is the water stress coefficient calculated following the method described in a previous study ${ }^{44}$ as a function of the soil water content in the root zone $(S)$, the maximum and actual water content in the root zone. For rainfed crop $i$ on day $t, k_{\mathrm{s}, i, t}$ was evaluated as:

$$
k_{s, i, t}=\left\{\begin{array}{cl}
\frac{S_{i, t}}{\left(1-p_{i}\right) S_{\max , i}} & \text { if } S_{i, t}<\left(1-p_{i}\right) S_{\max , i} \\
1 & \text { if } S_{i, t} \geq\left(1-p_{i}\right) S_{\max , i}
\end{array}\right.
$$

where $S_{i, t}$ is the depth-average soil moisture (expressed as a length), $S_{\max , i}$ is the value of available soil moisture, and $p_{i}$ is the fraction of $S_{\max , i}$ that a crop can uptake from the rooting zone as calculated in previous works ${ }^{44,45}$. In the case of irrigated crops, $k_{\mathrm{s}, i t}$ was assumed to be 1 to represent conditions of no water stress, following an earlier study ${ }^{40}$. For a given crop and grid cell, $S_{i, t}$ was calculated by solving a daily soil water balance:

$$
S_{i, t}=S_{i, t-1}+\Delta t\left(P_{e f f, t}+I_{i, t}-E T_{a, i, t}-D_{i, t}\right)
$$

where $S_{i, t-1}$ is the soil moisture of the previous time step, $\Delta t$ is equal to one day, $P_{\text {eff }, t}$ is the effective precipitation (that is, the rainfall that is actually absorbed in the soil and not directly evaporated from the surface), $I_{i, t}$ is the additional irrigation water (used only in the case of irrigated crops) and $D_{i, t}$ is deep percolation below the root zone (which occurred when soil moisture exceeded field capacity (that is, the volume of water able to be retained in the soil)). Using a method from the literatur ${ }^{46}$, daily precipitation was generated from monthly rainfall by using a mixed Bernoulli Gamma distribution function ${ }^{47}$, where the Bernoulli distribution was used to first randomly distribute the number of wet days over the month and the Gamma distribution was then used for the random distribution of precipitation over the wet days. Daily precipitation was then converted to $P_{\text {eff, } t}$ using the Soil Conservation Service method (for example, see refs $40,44,48$ ).

Thus, for each day, each crop and each grid cell, we were able to calculate a rainfed $\mathrm{ET}_{\mathrm{ai}, \text { trainfed }}$ - equal to the 'green' consumptive water use, and irrigated $\mathrm{ET}_{a, i, t, i r r i g a t e d}-$ equal to the potential evapotranspiration under no water stress. Blue consumptive water use was calculated as the difference between $\mathrm{ET}_{\mathrm{a}, i, \mathrm{t} \text {,irrigated }}$ and $\mathrm{ET}_{\mathrm{a}, \mathrm{i}, \mathrm{t} \text { rainfed }}$ and was only considered for irrigated crops. We then took a summation of the daily green and blue consumptive water use across a crop's entire growing season to determine total green (for rainfed and irrigated crops) and blue (for irrigated crops only) consumptive crop water use (GWU and BWU, respectively) (Supplementary Table 3). These definitions of GWU and BWU are consistent with standard methodologies of water footprint calculation (see ref. ${ }^{40}$ ) (Supplementary Table 17).

Current production and water demand. For each pixel where at least one of the rainfed crops considered here was grown, current (year 2000) rainfed production, $p_{c}$, was calculated as:

$$
p_{c}=\sum\left(y_{i} a_{i}\right)
$$

where $y_{i}$ is the rainfed yield of crop $i$, and $a_{i}$ is the rainfed harvested area of crop $i$. These calculations were repeated separately for irrigated croplands. The combined totals of current rainfed and irrigated production for each crop agreed well with those reported in FAOSTAT ${ }^{35}$ (Supplementary Table 14). Crop yields, which were originally reported in tonne ha ${ }^{-1}$, were converted to $\mathrm{kcal} \mathrm{ha}^{-1}$ and $\mathrm{kg}$ protein ha ${ }^{-1}$ using global values from FAOSTAT ${ }^{35}$ (Supplementary Table 18). While multicropping (that is, multiple crops harvest per year) occurs in a host of agriculturally important regions ${ }^{5}$, we did not attempt to disaggregate irrigated and rainfed production further between different growing seasons as planting dates vary widely across cultivated areas. This consideration may therefore limit the number of replacement options for a given crop and region.

Current green and blue consumptive water demand of a cultivated pixel, $w_{c, g}$ and $w_{\mathrm{c}, \mathrm{b}}$ respectively (expressed in $\mathrm{m}^{3} \mathrm{yr}^{-1}$ ), in irrigated cropland was calculated following a published method $^{49}$ as:

$$
w_{c, g}=\sum\left(10 G W U_{i} a_{i}\right) \text { and } w_{c, b}=\sum\left(10 B W U_{i} a_{i}\right)
$$

where $\mathrm{GWU}_{\mathrm{i}}$ and $\mathrm{BWU}_{i}$ are the green and blue consumptive water use (expressed in $\mathrm{mm} \mathrm{yr}^{-1}$ ) for crop $i$ and the factor 10 converts the units for evapotranspiration to $\mathrm{m}^{3} \mathrm{ha}^{-1} \mathrm{yr}^{-1}$. Only $w_{c, g}$ was calculated for rainfed croplands in each pixel. Our estimates of green and blue water demand agreed well with published values ${ }^{40}$ (Supplementary Table 17).

Interpolating yields. To estimate yields for the replacement scenario, maps of current rainfed and irrigated crop yields (28 in total) were interpolated using the ArcGIS 'Spline with Barriers' tool. This tool "applies a minimum curvature method, as implemented through a one-directional multigrid technique that moves from an initial coarse grid, initialized in this case to the average of the input data, through a series of finer grids until an approximation of a minimum curvature surface is produced at the desired row and column spacing" ${ }^{30}$. This technique also ensured that splines were fit for each crop yield map and for each country independently, as stark discontinuities can occur at country borders (Supplementary Table 19). For each interpolated crop-specific rainfed yield map, we then applied two masks: (1) a cultivated area mask to consider only those rainfed areas where at least one of the 14 crops is currently grown; and (2) a buffering mask, which considers all pixels within a $25 / 12^{\circ}$ (or $\sim 250 \mathrm{~km}$ ) Euclidean distance from where the crop is currently cultivated to ensure that our analysis considered only those interpolated areas with similar climate characteristics. This masking was repeated separately for irrigated crops and irrigated areas. Our examination of agro-ecological suitability supported this assumption, showing only modest variation in suitability (14\%) within the $25 / 12^{\circ}$ buffer. Of course, even if climate and soil conditions are suitable, 
certain crops may not currently be grown in a given area for a host of other reasons (such as a lack of indigenous knowledge, infrastructural constraints, dietary preferences and so on). However, at the distances we consider, there are probably minimal obstacles that would prevent the transfer of knowledge, technology, and agricultural inputs from locations where a crop is currently grown. Thus while these considerations were beyond the scope of this study, they should be kept in mind when considering the approach and findings presented here.

Minimizing water demand. Our replacement approach sought to minimize consumptive water use $\left(\mathrm{m}^{3} \mathrm{ha}^{-1}\right)$ for each pixel within currently cultivated lands without inducing decreases in caloric yield, protein yield, or farmer price. We performed this replacement approach separately for irrigated and rainfed croplands. The first approach we describe is for irrigated croplands. Because a single pixel could contain harvested areas for multiple irrigated crops, we assessed each irrigated harvested area within each pixel separately, starting with the crop with the largest harvested area and working towards the smallest. For the harvested area of interest, we applied a set of criteria aimed at minimizing the blue water footprint of irrigated crop production through the redistribution of cropping patterns. To do this, we replaced an existing crop with a crop that minimizes blue water use, provided that the following conditions were also met: (1) that green crop water requirement should not increase; (2) that calorie production should not decrease from current amounts; (3) that protein production should not decrease from current amounts; and (4) that the value of crop production should not decrease from current levels. Expressed together, the criteria form the multiconditional statement:

$$
\left(B W U_{\text {min }}<B W U_{c}\left|G W U_{\text {min }} \leq G W U_{c}\right| p_{\text {min }} \geq p_{c}\left|l_{\text {min }} \geq l_{c}\right| v_{\text {min }} \geq v_{c}\right)
$$

where $p$ is the crop protein yield (tonne ha $\left.{ }^{-1}\right), l$ is the crop calorie yield $\left(\mathrm{kcal} \mathrm{ha}^{-1}\right)$, $v$ is the crop value (that is, the producer price in US $\$ \mathrm{ha}^{-1}$ ), and the subscripts min and $c$ represent the potential replacement crop and the current crop, respectively. The values $p, k$, and $v$ were calculated as the product of the conventional yield (tonne ha ${ }^{-1}$ ) and the protein content (tonnes of protein per tonne), calorie content $\left(\mathrm{kcal}_{\text {tonn }} \mathrm{e}^{-1}\right.$ ), and value (US\$ tonn $\mathrm{e}^{-1}$ ) of the crop (Supplementary Table 18).

If all five criteria were met, the current irrigated crop in the harvested area of interest was replaced by the crop that minimizes blue consumptive water use. If at least one of the conditions was not met, we then repeated the assessment of the five criteria (equation (6)) using the irrigated crop with the next lowest BWU value for the pixel, and so on through all 14 crops. If no potential replacement crop met all five criteria for the harvested area, then the current crop was maintained. If a replacement occurred for the harvested area of interest, the replacement crop could not be further considered within the pixel, thereby largely preventing a transition to monoculture. However, preventing a loss of crop diversity in every case would have been computationally impractical because every permutation of yield, harvested area and water footprint would need to be considered for each pixel. Thus, there were some instances wherethe replacement crop in one harvested area was the same as the current crop in another harvested area for the same pixel. In $92 \%$ of the cultivated area, crop redistribution resulted in either no loss of crop diversity or only a reduction by one crop. Thus a crop may be replaced in a given harvested area, but each harvested area within a pixel is treated as fixed. Our approach therefore represents a combinatorial optimization in that we draw from a finite (that is, discrete) number of feasible solutions, all of which reduce consumptive blue water use. Our method does not necessarily attain the absolute minimum because it operates under the assumption that the areas cultivated with different crops remain the same whereas the crop types change. This assumption, however, ensures that crop diversity is overall conserved (except for certain small reductions noted above). This entire methodology was repeated for rainfed croplands with the only difference being that BWU was not considered among the replacement criteria as there is no irrigation component for rainfed production.

The replacement analysis for rainfed and irrigated crop production was also repeated for three other scenarios. In the first alternative scenario, the replacement criteria for rainfed crops remained the same; for irrigated crops, we removed the criterion for GWU, as it is possible for replacing crops to have a lower BWU and higher GWU relative to the current crop. In a second alternative scenario, we kept the original replacement criteria in place, with soybean areas held constant (we did not allow replacement) in case this might prevent any potential degradation of the soil nutrient pool. For the third, we held soybean, sugar beet and sugar cane areas constant for the same reason as the second alternative scenario as well as to avoid any impacts on biofuel production. For all four scenarios - no constant, no constant (based only on BWU for irrigated crops), constant soybeans, and constant soybeans/sugar beet/sugar cane - we found consistent benefits in terms of consumptive water demand and calorie and protein supply as a result of crop replacement (Supplementary Table 13). A summary of all data sets and sources is provided in Supplementary Table 20.

Water scarcity assessment. Water scarcity was calculated as the ratio of total consumptive water demand $\left(w_{\mathrm{c}, \mathrm{g}}+w_{\mathrm{c}, \mathrm{b}}\right)$ to the long-term average renewable water availability (1970-2000) for each of 10,105 watersheds within currently cultivated areas. Data on renewable water availability (surface + groundwater) came from a study ${ }^{17}$ that used the WaterGAP3 integrated global water resources model. These data include precipitation within the watershed and/or upstream inflows that are stored in or pass through the watershed and do not account for interbasin transfers or desalination ${ }^{17}$. Using long-term average renewable availability allows for an examination of whether freshwater withdrawals and consumption can be sustained by a watershed through time. If total consumptive water demand exceeds the average renewable water available (that is able to recharge annually) then the difference must be met through non-renewable sources (such as groundwater pumping) and can lead to the depletion of surface and groundwater sources.

Data availability. Spatially distributed crop-specific information on rainfed/ irrigated yields, rainfed/irrigated harvested area, and rainfed/irrigated agro-ecological suitability were taken from the FAO's Global Agro-ecological Zones (GAEZ) database ${ }^{36}$. Information on nutrient content was taken from the Global Extended Nutrient Supply (GENuS) database ${ }^{38}$ (Supplementary Table 2). Long-term average monthly precipitation data (10 arcmin; 19611990) were taken from the University of East Anglia's Climate Research Unit CRU CL2.0 data set ${ }^{39}$. Crop coefficients, planting dates, and growing stages were adapted from a previous study ${ }^{40}$ (Supplementary Table 16), and the same climate zones were used, adapted from an earlier work ${ }^{41}$ (Supplementary Fig. 15). The total available water capacity for the dominant soil ( $5 \mathrm{arcmin})$ came from the Harmonized World Soil Database ${ }^{42}$.

All of the data used in this study are publically available or included in the Supplementary Information. In addition, the data that support the findings of this study are available upon request from the corresponding author.

\section{References}

35. FAOSTAT Database (FAO, accessed 3 December 2016); http://www.fao.org/ faostat.

36. Global Agro-ecological Zones (GAEZ) v3.0 (IIASA/FAO, 2012).

37. Rulli, M. C. \& D'Odorico, P. Food appropriation through large scale land acquisitions. Environ. Res. Lett. 9, 064030 (2014).

38. Smith, M. R., Micha, R., Golden, C. D., Mozaffarian, D. \& Myers, S. S. Global Expanded Nutrient Supply (GENuS) Model: A new method for estimating the global dietary supply of nutrients. PLoS ONE 11, e0146976 (2016).

39. New, M., Lister, D., Hulme, M. \& Makin, I. A high-resolution data set of surface climate over global land areas. Clim. Res. 21, 1-25 (2002).

40. Mekonnen, M. M. \& Hoekstra, A. Y. The green, blue and grey water footprint of crops and derived crop products. Hydrol. Earth Syst. Sci. 15, 1577-1600 (2011)

41. Kottek, M., Grieser, J., Beck, C., Rudolf, B. \& Rubel, F. World map of the Köppen-Geiger climate classification updated. Meteorol. Zeit. 15, 259-263 (2006).

42. Harmonized World Soil Database v.1.2 (FAO/IIASA, 2012).

43. Global Map of Monthly Reference Evapotranspiration - 10 Arc Minutes (FAO, accessed 18 April 2017).

44. Allen, R.G., Pereira, L.S., Raes, D. \& Smith, M. Crop Evapotranspiration - Guidelines for Computing Crop Water Requirements Irrigation and Drainage Paper 56 (FAO, 1998)

45. Siebert, S. \& Döll, P. Quantifying blue and green virtual water contents in global crop production as well as potential production losses without irrigation. J. Hydrol. 384, 198-207 (2010).

46. Hoogeveen, J., Faurès, J.-M., Peiser, L., Burke, J. \& van de Giesen, N. GlobWat - a global water balance model to assess water use in irrigated agriculture. Hydrol. Earth Syst. Sci. 19, 3829-3844 (2015).

47. Wilks, D. S. \& Wilby, R. L. The weather generation game: a review of stochastic weather models. Prog. Phys. Geogr. 23, 329-357 (1999).

48. Soil Conservation Service A Method for Estimating Volume and Rate of Runoff in Small Watersheds Report No. SCS-TP-149 (US Department of Agriculture, 1968).

49. Tuninetti, M., Tamea, S., D’Odorico, P., Laio, F. \& Ridolfi, L. Global sensitivity of high-resolution estimates of crop water footprint. Water Resour. Res. 51, 8257-8272 (2015).

50. How Spline with Barriers Works (Environmental Systems Research Institute, 2017): http://desktop.arcgis.com/en/arcmap/10.3/tools/spatial-analyst-toolbox/ how-spline-with-barriers-works.htm. 